\title{
Keywords
}

intimate partner violence; intervention; mediation; Hispanics; HIV

Intimate partner violence (IPV) is a public health problem for all socioeconomic classes and cultures. However, IPV can be particularly problematic for Hispanic women who often lack access to and/or knowledge of relevant social services compared with non-Hispanics (U. A. Kelly, 2009). The lifetime prevalence rate of intimate partner rape, physical violence, and/or stalking among Hispanic women in the United States is slightly higher than non-Hispanic White women (37.1\% vs. $34.6 \%$ respectively; Black et al., 2011). Hispanic women have also been found to be more likely to suffer from the negative consequences of IPV such as being

\footnotetext{
Corresponding Author: Brian E. McCabe, School of Nursing and Health Studies, University of Miami, P.O. Box 248153, Coral Gables, FL 33124, USA. bmccabe@ miami.edu.

The contents of this article are solely the responsibility of the authors and do not necessarily represent the official views of the National Institutes of Health.

Declaration of Conflicting Interests

The author(s) declared no potential conflicts of interest with respect to the research, authorship, and/or publication of this article.
} 
more likely to suffer from the physical and psychological effects of abuse, including homicide (Author, 2009; Bonomi, Anderson, Cannon, Slesnick, \& Rodriguez, 2009; Caetano, Ramisetty-Mikler, \& McGrath, 2004). These disparities may be related to Hispanic victims of IPV being less likely to report abuse and facing barriers to culturally appropriate social services and health care (Bloom et al., 2009; U. A. Kelly, 2009). These barriers include lack of knowledge of where to access help, linguistic/cultural factors, low insurance coverage, legal status, and mistrust of authorities (Author, 2011; Bloom et al., 2009; Denham et al., 2007; Ingram, 2007).

Klosterman (2006) argued that the creation of IPV prevention interventions that directly address the victim of IPV instead of only the person who commits that abuse might lead to greater IPV reductions. There is limited evidence for the effectiveness of traditional intervention programs that enroll only the perpetrator. A meta-analysis of 22 efficacy trials for batterer intervention programs found that overall these programs have a small effect on recidivism of violence (Babcock, Green, \& Robie, 2004). In addition, interventions that directly address IPV may not be accessed or wanted by victims or perpetrators of IPV. Domestic violence treatment programs often only accept legal referrals; consequently, these programs only reach victims of IPV who have intimate partners who have been arrested. As Hispanic victims are less likely to report IPV, they are unlikely to access services labeled as related to domestic violence. They may also shy away from these interventions due to mistrust of authorities or to protect their partners against the negative legal consequences of IPV (Author, 2011; Bloom et al., 2009). An alternative approach for IPV reduction interventions is to reach victims as they engage with other health promotion services.

There is evidence linking IPV to HIV risk, which suggests that interventions for HIV risk and IPV could be integrated. In a recent review, Campbell et al. (2008) showed that a history of IPV increases HIV risk via several pathways, including increased sexual risk behaviors in victims and perpetrators, psychological and physiological consequences of violence that facilitate HIV transmission (e.g., being immune compromised), forced sex with an infected partner, and the inability of victims to negotiate safer sex practices. Hispanic women who report experiencing IPV have about six times greater odds of having a sexually transmitted infection (STI) than their peers (Author, 2008). Davila, Bonilla, Gonzalez-Ramirez, Grinslade, and Villarruel (2008) reported a high prevalence and interrelatedness of HIV and IPV for Hispanics and argued for integration of current services designed for HIV-risk reduction and IPV prevention programs. A similar case has been made in regard to the links between substance abuse and IPV and the need to integrate services that address these conditions (Amaro, Chernoff, Brown, Arévalo, \& Gatz, 2007; Author, 2008).

Several studies have shown that integrating IPV prevention or reduction strategies into other interventions can be successful. In the Stepping Stones project (Jewkes et al., 2008), a 50-hr HIV prevention program in South Africa, men were less likely to report IPV perpetration and problem drinking at a 12-month follow-up after receiving the curriculum. Another integrated violence and HIV-risk intervention for men (Kalichman et al., 2009) based in South Africa was shown to reduce violence against women 6 months post-intervention. Gilbert and colleagues (2006) reported that a combined metha-done maintenance relapse prevention and relationship safety intervention for women decreased IPV (sexual, physical, 
and psychological) and drug use at 3-month follow-up. However, Stuart and colleagues (2003) found that initial reductions in IPV at 6 months had diminished over a full year for men in an intensive outpatient alcohol dependence treatment program.

Given the barriers that Hispanic women face in accessing IPV-related services, there is a need for Hispanic women to have opportunities to access interventions through nontraditional venues. One such approach that could be used to increase access to IPV-related interventions is to incorporate them into existing community-based programs that Hispanic women access, such as substance use and/or HIV-risk reduction programs. The Centers for Disease Control and Prevention (CDC; 2009) listed six best-evidence HIV prevention programs for Hispanics in the compendium of evidence-based HIV prevention interventions. To date, four additional interventions for adult Hispanic women not listed in that compendium have been formally evaluated and reported in the literature (El-Bassel, Gilbert, Wu, Go, \& Hill, 2005; Harvey et al., 2004; Raj et al., 2001). Of these interventions, only one —SEPA (Salud [health], Educación [education], Promoción [promotion], y [and] Autocuidado [self-care])—has been shown to reduce IPV (Author, 2012).

Investigating mechanisms of IPV reductions in SEPA could lead to greater understanding of how to integrate IPV prevention/reduction into other interventions for Hispanic women. To our knowledge, no studies have tested mechanisms of action of the change in IPV in interventions for substance use disorders or HIV risk. There are several additional reasons to test mediation of interventions. Understanding how treatment change is produced advances theoretical understanding (La Greca, Silverman, \& Lochman, 2009). Kazdin \& Nock (2003) noted that examining the mechanisms by which interventions work is vital to improve the clinical field. For clinicians, understanding what to change allows flexibility to adapt to patient needs, problems, and contexts (La Greca et al., 2009).

\section{Mechanisms of Change}

SEPA is a culturally specific, community-based HIV prevention program for Hispanic women that has been examined twice in randomized trials with Hispanic women (Author, 2005; Author, 2012). IPV was not assessed in the first trial of SEPA, but was examined in the second trial (Author, 2012). SEPA is based on social-cognitive theory which supports the idea that individuals learn best by observing others perform the targeted behavior and activities that provide the knowledge and skills to perform such behaviors (Glanz, Rimer, \& Lewis, 2002). As such, healthy communication strategies were imparted on the participants through identifying healthy communication strategies and providing opportunities for the participants to observe and practice these strategies with a partner. We chose to evaluate whether the changes in partner communication about HIV and/or alcohol intoxication were the mechanism(s) of the reduction in IPV in SEPA because (a) partner communication about HIV and alcohol have been linked theoretically and empirically to IPV in this sample (Author, 2012) and (b) SEPA reduced alcohol intoxication and maintained partner communication about HIV relative to controls (Author, 2012). To extend the focus on couples violence more broadly, this study also examined whether SEPA had an effect on female-to-male IPV, possible mediators of changes in female-to-male IPV, and whether 
changes in female-to-male IPV were associated with changes in male-to-female IPV (see Figure 1 for our model of intervention mechanisms).

Although little quantitative research with Hispanics has described the relationship between partner communication about HIV and IPV, qualitative research has identified healthy communication between couples as an important protective factor against IPV (Author, 2011). Babcock, Waltz, Jacobson, and Gottman (1993) noted that in couples with poor communication styles (e.g., wife demand/husband withdraw), the men are more likely to be violent.

More extensive research exists to support the relationship between alcohol intoxication and IPV (Stuart, 2005). For example, findings from the National Alcohol Survey (NAS), a population-based study with a multi-staged probability sample of households, including cohabitating couples, has documented the strong association between alcohol use problems and both male-to-female and female-to-male IPV for White, Black, and Hispanic couples (Caetano, Schafer, \& Cunradi, 2001). A more in-depth analysis of these data by Schafer, Caetano, and Cunradi (2004) identified alcohol problems as a significant mediator of the relationship between a history of child abuse and adult IPV perpetration and victimization. Similar links between alcohol use and IPV have been found in other samples, such as soldiers (Bell, Harford, Fuchs, McCarroll, \& Schwartz, 2006) and Hispanic women (Author, 2008).

The following objectives were developed based on the conceptual framework described above. In the parent trial (Author, 2012), SEPA had significant intervention effects on maleto-female IPV, alcohol intoxication, and partner communication about HIV. Tests of intervention effects from the original report were re-analyzed to test mediation for the current investigation. The intervention effect on female-to-male IPV and mediation of IPV were not tested previously. Our objective was to examine mediation of intervention effects on IPV. We hypothesized as follows:

Hypothesis 1: There will be an intervention effect on IPV.

Hypothesis 2: There will be an intervention effect on mediators over time (increased partner communication about HIV; reduced alcohol intoxication relative to the control condition).

Hypothesis 3: There will be a relationship between change in mediators and change in outcomes (reduced IPV).

\section{Method}

\section{Design and Procedures}

This study is a secondary analysis of data from a randomized controlled experimental trial with adult Hispanic women in South Florida that compared SEPA with a delayed intervention control group (Author, 2012). Women completed measures at four assessments: baseline and 3, 6, and 12 months post-baseline between January 2008 and April 2010. Recruitment was with outreach (e.g., churches, supermarkets, community organizations) and flyers. After informed consent, women were interviewed (in either English or Spanish) by 
trained bilingual (Spanish and English) female research staff using a structured interview. Most women $(504,92 \%)$ chose to complete the interview in Spanish. A secure web-based software system (e-Velos) was used for data entry. Participants received US\$50 per interview and US\$20 per group session. This study was approved by the University of Miami and the Miami-Dade County Health Departments Institutional Review Boards.

\section{Sample}

To be eligible for the trial, women had to self-identify as Hispanic, be between 18 and 50 years old, and report sexual activity in the last 3 months. A total of 548 women were randomized using a permuted-block randomization procedure. There were no significant baseline differences (see Table 1) between conditions. Women were born in several nations: Colombia (34\%), Cuba (13\%), and 10\% or fewer were born in 1 of 14 other nations.

\section{Intervention and Interventionists}

SEPA is an HIV-risk reduction intervention for Hispanic women. The content and activities were derived from the social-cognitive model (Bandura, 1977), with structured activities to promote self-efficacy (e.g., condom use demonstration, communication activities). Content delivery was informed by Freire's (1970) pedagogy, that is, it was important that every individual in the group contributed to the knowledge and skills generated during the session, which provided an atmosphere that encouraged participants to engage in discussion and activities. SEPA was five 2-hr small-group sessions ( $M=4.79$ women, $S D=1.97) ; 163$ (60\%) women attended at least one session, with 119 (73\%) of those who attended one session going on to attend all sessions (Author, 2013). All women were included in these intention-to-treat (ITT) analyses reported here. ITT analysis retains every participant randomized to either intervention condition, regardless of any events that happen after randomization, such as not participating in the intervention. This strategy is more similar to actual clinical practice and leads to more conservative, that is, smaller, estimates of intervention effects. Session topics were HIV/AIDS in the Hispanic community, STI, HIV/ AIDS prevention (e.g., condom use), negotiation and communication with romantic partners, IPV, and substance abuse. Five bilingual/bicultural Hispanic female facilitators with a range of education (bachelors to doctoral) delivered the group intervention in English or Spanish (based on the women's preference) at community sites. At the 6-month follow-up, women in SEPA were invited to a booster session to discuss topics related to the intervention; only 31 (11\%) women attended these boosters. Women were not compensated for the boosters. Facilitator training, an intervention manual, and a standardized presentation covering the content and activities of each session aided intervention fidelity. The study's principal investigator (PI) also conducted unannounced visits to groups led by each of the facilitators to assess and address fidelity.

\section{Measures}

All measures have been used in previous research with Hispanics, were in Spanish and English, and assessed a 3-month period.

Intimate Partner Violence (IPV) was assessed with two subscales (Partner-to-You and the You-to-Partner) from the Revised Conflict Tactics Scale short form (Straus \& Douglas, 
2004) that was adapted for Hispanic women in this study by reducing the number of items, simplifying wording, and shortening the response scale from eight options to four (never, one time, two times, or three or more times). The measure assesses the frequency of 12 behaviors in the past 3 months (e.g., insulted you, beat you up, forced you to have sex) which are summed for two total scores, one for male-to-female IPV and one for female-tomale IPV. In this sample Cronbach's alpha on these scales was above .84 at all assessments. To account for positive skew in the analysis, both scales were coded as $1=$ any reported IPV, $0=$ no reported IPV. At baseline, 301 (55\%) women reported both male-to-female and female-to-male violence, 49 (9\%) reported only male-to-female violence, and $29(5 \%)$ reported only female-to-male violence.

Partner communication about HIV was measured with the Communication With Partner scale (Catania et al., 1995) that was adapted for use with Hispanic women in this study. The scale contains 10 items (e.g., Asked your partner(s) how he/she felt about using condoms before you had intercourse) concerning whether the respondent discussed topics related to HIV with their primary sexual partner in the past 3 months. Reliability was good across all assessments (as > .86). To account for positive skew, a positive response to any of these behaviors was coded as 1 ; none was coded as 0 . This scale assessed communication about HIV-risk, but we believe that items also reflected underlying communication skills (e.g., negotiation, open exchange of information) that are relevant in non-risk areas. The original scale asked about communication with a first-time sexual partner; the adapted scale elicited the same information in relation to the woman's main partner.

Alcohol Intoxication was assessed with an item (In the past 3 months, how often have you been drunk on alcohol?) from a substance abuse instrument adapted from J. A. Kelly and colleagues (1994). This measure of alcohol use was included in the trial because it had been used in previous research on HIV-risk reduction. To account for positive skew, in analyses, this variable was coded $1=$ intoxicated versus $0=$ not intoxicated .

\section{Analytic Strategy}

The parallel process method (Cheong, MacKinnon, \& Khoo, 2003) was used to test mediation. Criterion for mediation were (a) an intervention effect on change in the outcome, (b) an intervention effect on the proposed mediator, (c) change in the mediator related to change in the outcome, and (d) a nonzero indirect effect from intervention to change in mediator to change in outcome. Hypotheses were tested with latent growth curve models (LGM) in Mplus 6.1 (Muthén \& Muthén, 2010). Full information maximum likelihood estimation allowed inclusion of all cases regardless of missing data. Analysis from the parent trial of SEPA (Author, 2012) showed significant intervention effects on male-tofemale IPV, alcohol intoxication, and partner communication about HIV. These effects were re-analyzed in LGM, with linear change in male-to-female IPV and alcohol intoxication, and linear plus quadratic (i.e., curvilinear) change in partner communication about HIV. Analyses from Author (2012) indicated that covariance between members of the same group did not affect the intervention effects, so was not included here. The intervention effect on female-to-male IPV was not analyzed in the original study. Following the strategy in Author (2012), we compared the fit of two trajectories of change in female-to-male IPV. We believe 
it is important to examine the fit of curvilinear trajectories, as intervention effects may diminish over time. Linear change (Bayesian information criterion $[\mathrm{BIC}]=2,766.14$ ) fit better than linear and quadratic change $(\mathrm{BIC}=2,788.25)$ for female-to-male IPV. With the BIC (Schwarz, 1978), lower values suggest better fit.

Intervention effects on changes in each outcome and mediator were examined separately, with intervention condition entered as a dummy-coded predictor $(0=$ control, $1=$ intervention). Figure 2 shows the generic mediation model. The latent intercept was set at 3 months to test for differences at the 3-month follow-up (the first assessment post-treatment). A difference in mediator, but not outcome, at this point would suggest temporal precedence. Third, LGM with one outcome and one mediator were combined into a single parallel process model. In this step, relationships between changes in variables from baseline to 12month follow-up were tested. Each outcome-mediator pair was tested separately, with the path from treatment condition to the mediator (path a) and from the mediator to the outcome (path $b$ ). The path from intervention condition to the outcome was represented by $c$ when not controlling for the mediator and $c^{\prime}$ when the mediator was controlled. In models with quadratic change, $d$ and e paths were added. Fourth, we tested for a non-zero indirect effect, defined by the product $a \times b$ or $d \times e$ (MacKinnon, Lockwood, Hoffman, West, \& Sheets, 2002).

\section{Results}

\section{Intervention Effects on IPV}

Intervention effect on male-to-female IPV was similar to the original report (Author, 2012). Women in SEPA had greater reductions in male-to-female IPV than controls, $B=-0.35, S E$ $=0.13, p=.010$. Female-to-male IPV was not examined in Author, 2012; SEPA had greater reductions in female-to-male IPV, $B=-0.36, S E=0.14, p=.007$. Graphs of estimated trajectories of IPV, partner communication about HIV, and alcohol intoxication in both intervention conditions are in Figure 3.

\section{Intervention Effects on Mediators}

The intervention effects on partner communication about HIV and alcohol intoxication were similar to the original report (Author, 2012). SEPA maintained partner communication about HIV and reduced alcohol intoxication compared with controls. Table 2 shows the results of mediation analyses (Hypotheses 2 and 3)

\section{Relationships Between Mediators and Outcomes}

Change in partner communication about HIV, but not alcohol intoxication, mediated the intervention effect on male-to-female IPV. Neither partner communication about HIV or alcohol intoxication mediated the intervention effect on female-to-male IPV.

\section{Temporal Precedence}

There were no significant differences at 3 months post-baseline in male-to-female IPV, $B=$ $0.15, S E=0.25, p=.551$; female-to-male IPV at 3 months post-baseline, $B=-0.10, S E=$ 
0.23, $p=.668$; partner communication about HIV, $B=0.43, S E=0.25, p=.084$; or alcohol intoxication, $B=0.08, S E=0.53, p=.877$.

\section{Reverse Paths}

Male-to-female IPV was not related to linear change, $B=-0.97, S E=2.22, p=.661$, or quadratic change, $B=1.95, S E=1.60, p=.223$, in partner communication about HIV.

\section{Inter-Relationships of IPV}

Change in female-to-male violence was significantly related to male-to-female violence, $B=$ 1.73, $S E=0.25, p<.001$, but the indirect effect was not significant, $B=-0.31, S E=0.25, p$ $=.210$. Change in male-to-female violence was significantly related to change in female-tomale violence, $B=2.40, S E=0.04, p<.001$, and the indirect effect was significant, $B=$ $-1.21, S E=0.24, p<.001$. In other words, reductions in male-to-female IPV mediated the reductions in female-to-male IPV related to SEPA, but not the other way around.

\section{Discussion}

The present study was a secondary analysis of data from a trial of an HIV-risk reduction intervention (SEPA) for Hispanic women (Author, 2012) that integrated IPV reduction strategies. To our knowledge, this is the first manuscript to report mechanisms of action of an intervention that integrated IPV prevention/reduction strategies into an HIV-risk reduction intervention. The parent trial showed that SEPA reduced male-to-female IPV, decreased alcohol intoxication, and maintained partner communication about HIV compared with a delayed-treatment control group. Results from this secondary analysis showed that SEPA also reduced female-to-male IPV compared with controls. This study supported partner communication about HIV as a mediator of IPV reduction, which may inform intervention adaptation/development. Alcohol intoxication was not a mediator.

\section{Research Implications}

SEPA prevented deterioration in partner communication about HIV, which reduced the likelihood of IPV. The absence of reverse mediation (i.e., IPV as a mediator of partner communication about HIV) strengthened the conclusion that change in partner communication about HIV was a mechanism of intervention effects on male-to-female IPV. Interestingly, partner communication about HIV was not a mediator of change in condom use in Author (2012). There was also evidence that reductions in male-to-female IPV mediated reductions in female-to-male IPV. There was no evidence that partner communication about HIV or alcohol intoxication mediated the intervention effect on female-to-male IPV. However, reductions in male-to-female IPV mediated change in femaleto-male IPV.

The linear and quadratic change components of partner communication about HIV indicated higher levels in SEPA than for controls over the first 6 months of the follow-up period, although this difference shrank over the second 6 months of follow-up. That is, over the first 6 months of follow-up, SEPA prevented the deterioration of partner communication about HIV that was evident in untreated women, but partner communication about HIV was 
becoming more similar between groups at 12 months as the intervention effect stabilized. This study was not able to determine the cause of deterioration in communication for untreated women. With respect to mediation, given that the quadratic change in partner communication about HIV was not related to change in IPV and there was no evidence of an increase in IPV at 12 months, it is likely that IPV stabilized at a reduced level over time as the non-violent behaviors in the couple relationship became self-reinforcing. However, it is possible that if women were followed for more than 1 year, improvements in IPV might diminish, as the intervention effect on partner communication about HIV diminished. Although longer follow-ups for intervention studies create feasibility problems, a longer follow-up is needed to fully understand consolidation of intervention-related change over time.

The fact that modest intervention effect on partner communication about HIV was linked to reductions in IPV suggests that including strategies to address communication are likely to have a high "rate of return" in interventions for IPV and sex risk behaviors. Furthermore, the results provided some information on how to combine IPV reduction with HIV-risk reduction interventions by suggesting a cascade of changes over time from woman's behavior (communication) to partner's behavior (male-to-female IPV) to woman's behavior (female-to-male IPV). The first sequence of changes was that SEPA maintained partner communication about HIV, which presumably led to fewer relationship conflicts or better management of conflicts compared with controls. As the partner was less likely to use IPV, the woman was less likely to retaliate or defend herself with IPV. It is important to note that although male-to-female IPV was related to female-to-male IPV, the results of violence from men are often more severe and lethal than from women. Future studies should examine the relational processes following SEPA in more detail.

\section{Limitations}

A limitation of the parallel process growth model is that temporal precedence cannot be definitively established. We attempted to examine temporal precedence in two additional ways. We tested for intervention effects at a single time point by setting the latent intercept of the growth models at the 3-month assessment, that is, the first post-intervention assessment, but this strategy did not examine timing of changes directly. The lack of significant indirect effects when paths were reversed lent some support to the hypothesized directions of influence, but was not definitive. We recommend future studies have more frequent assessments of IPV and communication to assess the direction of changes. Without random assignment to levels of communication, there was no way to rule out the possibility that other variables were responsible for changes in both partner communication about HIV and IPV. It may be that SEPA produced broad changes in interaction patterns (e.g., empowerment) and that intervention effect on partner communication about HIV was only one aspect of the broader changes. Future studies should investigate how intervention strategies lead to change in partner communication about HIV and how change in partner communication about HIV is related to other changes.

There are several other limitations to note when interpreting the results of this study. All measures were self-report. Self-report measures may be biased, particularly when socially 
undesirable behaviors, for example, IPV and alcohol intoxication, are assessed. The measure of male-to-female and female-to-male IPV was based on the Revised Conflict Tactics Scale short form (Straus \& Douglas, 2004). This measure has been criticized for leading to underre-porting by respondents; lack of information regarding the greater context and motives for behavior, for example, if a woman is using conflict tactics as a result of her victimization; and including acts with great variation in severity, for example, kicking versus slapping (DeKeseredy \& Schwartz, 1998). Furthermore, because IPV was dichotomized (reporting any acts vs. no acts of violence), this study cannot specify what acts of violence were reduced. The single-item measure of alcohol use may have reduced response variability; future studies should consider using measures with more items to assess for substance use. The outcome indicators in this study were dichotomous, which typically reduces statistical power. It is important to note that testing mediation with continuous latent variables mitigates against this loss of statistical power. During an initial assumption testing period, a number of alternative transformations of the outcome and mediator variables were attempted, but none were acceptable. We have found many Hispanics endorse extremes of the response scale, and recommend the development/adaptation of measures that will produce greater variability for Hispanics.

IPV was only assessed from the woman's perspective, and no measures of partner behavior were assessed either from the male's perspective or by a third party. Engagement in SEPA (only $60 \%$ of women randomized attended at least one session) was less than ideal, which likely attenuated treatment effects. Finally, women were not randomly selected from the population of Hispanic women, so caution should be used for generalizations. It is not clear how well this intervention would generalize to a more naturalistic context. A trial of SEPA, with only three sessions, is currently in progress at a community-based service provider.

\section{Clinical and Policy Implications}

This study has important implications for the prevention of IPV and associated behaviorally rooted conditions. The findings about communication mediating intervention effects on IPV and the reciprocal relationships between male IPV and female IPV are generally consistent with the Dynamic Developmental Systems perspective (Capaldi \& Langhinrichsen-Rohling, 2012). From this perspective, IPV must be understood in dyadic and contextual terms. That is, IPV is often reciprocal between partners and related to a lack of relationship skills (e.g., healthy communication skills). Quality of communication appears to be a key component for establishing healthy intimate relationships that are characterized by the use of non-abusive and/or non-violent tactics to avoid and/or resolve conflict. Because communication is often addressed by interventions addressing other health problems, such as HIV and substance abuse, these results suggest that IPV prevention/reduction strategies can be easily incorporated into pre-existing health promotion and disease prevention programs.

Alternatively, because healthy communication appears to be a common protective factor across various health conditions, interventions that primarily focus on promoting healthy communication between couples could be developed to address multiple health conditions at one time. These development efforts may lead to more cost-effective and efficient methods of eliminating health disparities affecting Hispanics and improving population health more broadly (Author, 2009). 


\section{Acknowledgments}

Funding

The author(s) disclosed receipt of the following financial support for the research, authorship, and/or publication of this article: This research was funded by the Center of Excellence for Health Disparities Research: El Centro, National Institute of Minority Health and Health Disparities grant 2P60MD002266 (Nilda P. Peragallo, principal investigator) and The National Institutes of Health Office of Research on Women's Health.

\section{Biography}

Brian E. McCabe is a research assistant professor in the School of Nursing and Health Studies at the University of Miami. He earned his PhD in counseling psychology at the University of Miami. He completed his doctoral psychology internship at the VA Ann Arbor HealthCare System/University of Michigan, has master's degrees in community counseling and mental health counseling from Indiana University, and has a BA in psychology from Purdue University. He teaches courses on statistical analysis for health care and behavioral sciences. His research interests are the etiology and treatment of mental health and substance use disorders, health disparities in the incidence of and interventions for substance use and mental health disorders, longitudinal analysis methods, and the influence of culture on psychological measurement. He is currently the principal investigator on two projects that examine alcohol and drug screening and intervention for college students.

Rosa M. Gonzalez-Guarda is an assistant professor at the University of Miami School of Nursing \& Health Studies. She graduated from Georgetown University with a bachelor in the science of nursing (BSN), from Johns Hopkins University with a master's in nursing and public health (MPH), and from the University of Miami with an interdepart-mental doctorate in nursing, epidemiology, and psychology $(\mathrm{PhD})$. In the past, she has worked on community health nursing projects, public health programs, and research targeting African Americans, Hispanic Americans, and other vulnerable populations in Europe, Latin America, and the Caribbean. Her current research focuses on the intersection of substance abuse, intimate partner violence, and risky sexual behaviors among Hispanics and the development of culturally tailored interventions to address these. She is the PI of a community-based participatory research study aiming to develop a domestic violence prevention program for Hispanics in Miami-Dade County. She is also currently serving as a committee member for an Institute of Medicine and Robert Wood Johnson Foundation joint initiative on the future of nursing.

Nilda P. Peragallo is professor and dean of the University of Miami School of Nursing \& Health Studies. Her clinical specialty is in public health nursing, and her research interests include HIV/AIDS prevention in Latino women. She teaches public health nursing research, special topics in nursing research, nursing science, and program planning and evaluation. She completed a doctor of public health at the University of Texas, a master of science in nursing at the University of West Virginia, and a bachelor of science in nursing at the University of Chile.

Victoria B. Mitrani is professor and associate dean for research at the University of Miami School of Nursing and Health Studies. She completed a BA and a PhD in psychology at the 
University of Miami. She is a licensed psychologist with clinical specialization in family therapy. Her research focuses on family process and family intervention in populations affected by substance abuse and HIV. She directs the SONHS PhD program and teaches quantitative research methods and research ethics in the $\mathrm{PhD}$ program. She is the coprincipal investigator and research director of the Center of Excellence for Health Disparities Research: El Centro. She serves as vice-chair of the University of Miami Social Behavioral Sciences Institutional Review Board.

\section{References}

Amaro H, Chernoff M, Brown V, Arévalo S, Gatz M. Does integrated trauma-informed substance abuse treatment increase treatment retention? Journal of Community Psychology. 2007; 35:845862. doi:10.1002/jcop.20185.

Babcock JC, Green CE, Robie C. Does batters' treatment work? A meta-analytic review of domestic violence treatment. Clinical Psychology Review. 2004; 23:1023-1053. doi:10.1016/j.cpr. 2002.07.001. [PubMed: 14729422]

Babcock JC, Waltz J, Jacobson NS, Gottman JM. Power and violence: The relation between communication patterns, power discrepancies, and domestic violence. Journal of Consulting and Clinical Psychology. 1993; 61:40-50. [PubMed: 8450106]

Bandura, A. Social learning theory. Prentice Hall; Englewood Cliffs, NJ: 1977.

Bell NS, Harford TC, Fuchs CH, McCarroll JE, Schwartz CE. Spouse abuse and alcohol problems among White, African American, and Hispanic U.S. Army soldiers. Alcoholism: Clinical and Experimental Research. 2006; 30:1721-1733. doi:10.1111/j.1530-0277.2006.00214.x.

Bloom T, Wagman J, Hernandez R, Yragui N, Hernandez-Valdovinos N, Dahlstrom M, Glass N. Partnering with community-based organizations to reduce intimate partner violence. Hispanic Journal of Behavioral Sciences. 2009; 31:244-257. doi:10.1177/0739986309333291.

Bonomi AE, Anderson ML, Cannon EA, Slesnick N, Rodriguez MA. Intimate partner violence in Latina and non-Latina women. American Journal of Preventive Medicine. 2009; 36:43-48. doi: 10.1016/j.amepre.2008.09.027. [PubMed: 19095164]

Caetano R, Ramisetty-Mikler S, McGrath C. Acculturation, drinking, and intimate partner violence among Hispanic couples in the United States: A longitudinal study. Hispanic Journal of Behavioral Sciences. 2004; 26:60-78. doi:10.1177/0739986303261812.

Caetano R, Schafer J, Cunradi CB. Alcohol-related intimate partner violence among White, Black, and Hispanic Couples in the United States. Alcohol Research \& Health. 2001; 25:58-65. [PubMed: 11496968]

Campbell JC, Baty ML, Ghandour RM, Stockman JK, Francisco L, Wagman J. The intersection of intimate partner violence against women and HIV/AIDS: A review. International Journal of Injury Control and Safety Promotion. 2008; 15:221-231. doi:10.1080/17457300802423224. [PubMed: 19051085]

Capaldi DM, Langhinrichsen-Rohling J. Informing intimate partner violence prevention efforts: Dyadic, developmental, and contextual considerations. Prevention Science. 2012; 13:323-328. [PubMed: 22744890]

Catania JA, Binson D, Dolcini MM, Stall R, Choi K, Pollack LM, Coates TJ. Risk factors for HIV and other sexually transmitted diseases and prevention practices among US heterosexual adults: Changes from 1990 to 1992. American Journal of Public Health. 1995; 85:1492-1499. [PubMed: 7485660]

Centers for Disease Control and Prevention. Subset of best-evidence interventions, by characteristics. 2009. http://www.in.gov/isdh/files/Updated_Intervention_Recommendations.pdf

Cheong J, MacKinnon DP, Khoo ST. Investigation of mediational processes using parallel process latent growth curve modeling. Structural Equation Modeling. 2003; 10:238-263. doi:10.1207/ S15328007SEM1002_5. [PubMed: 20157639]

Davila YR, Bonilla E, Gonzalez-Ramirez D, Grinslade S, Villarruel AM. Pilot testing HIV and intimate partner violence prevention modules among Spanish-speaking Latinas. Journal of the 
Association of Nurses in AIDS Care. 2008; 19:219-224. doi:10.1016/j.jana.2007.10.005. [PubMed: 18457763]

DeKeseredy, WS.; Schwartz, MD. In brief: Measuring the extent of woman abuse in intimate heterosexual relationships: A critique of the conflict tactics scales. 1998. from http:// www.vawnet.org/Assoc_Files_VAWnet/AR_ctscrit.pdf

Denham AC, Frasier PY, Hooten EG, Belton L, Newton W, Gonzalez P, Campbell MK. Intimate partner violence among Latinas in Eastern North Carolina. Violence Against Women. 2007; 13:123-140. doi:10.1177/1077801206296983. [PubMed: 17251501]

El-Bassel N, Gilbert L, Wu E, Go H, Hill J. HIV and intimate partner violence among methadonemaintained women in New York City. Social Science \& Medicine. 2005; 61:171-183. doi: 10.1016/j.socscimed.2004.11.035. [PubMed: 15847970]

Freire, P. Pedagogy of the oppressed. Continuum; New York, NY: 1970.

Gilbert L, El-Bassel N, Manuel J, Wu E, Go H, Seewald R, Sanders G. An integrated relapse prevention and relationship safety intervention. Violence and Victims. 2006; 21:657-672. [PubMed: 17022356]

Gonzalez-Guarda RM. The Syndemic Orientation: Implications for eliminating Hispanic health disparities. Hispanic Health Care International. 2009; 7:114-115. doi:10.1891/1540-4153.7.3.114.

Glanz, K.; Rimer, BK.; Lewis, FM. Health behavior and health education: Theory, research and practice. Wiley; San Francisco, CA: 2002.

Gonzalez-Guarda RM, Peragallo N, Urrutia MT, Vasquez EP, Mitrani VB. HIV risks, substance abuse, and intimate partner violence among Hispanic women and their intimate partners. Journal of the Association of Nurses in AIDS Care. 2008; 19:252-266. doi:10.1016/j.jana.2008.04.001. [PubMed: 18598901]

Gonzalez-Guarda RM, Vasquez EP, Urrutia MT, Villarruel AM, Peragallo N. Hispanic women's experiences with substance abuse, intimate partner violence, and risk for HIV. Journal of Transcultural Nursing. 2011; 22:46-54. doi:10.1177/1043659610387079. [PubMed: 21191036]

Harvey SM, Henderson JT, Thorburn S, Beckman LJ, Casillas A, Mendez L, Cervantes R. A randomized study of a pregnancy and disease prevention intervention for Hispanic couples. Perspectives on Sex and Reproductive Health. 2004; 36:162-169. doi:10.1363/3616204.

Ingram EM. A comparison of help seeking between Latino and non-Latino victims of intimate partner violence. Violence Against Women. 2007; 13:159-171. doi:10.1177/1077801206296981. [PubMed: 17251503]

Jewkes R, Nduna M, Levin J, Jama N, Dunkle K, Puren A, Duvvury N. Impact of Stepping Stones on incidence of HIV and HSV-2 and sexual behavior in rural South Africa: Cluster randomized controlled trial. British Medical Journal. 2008; 337:a506-a517. doi:10.1136/bmj.a506. [PubMed: 18687720]

Kalichman SC, Simbayi LC, Cloete A, Clayford M, Arnolds W, Mxoli M, Kalichman MO. Integrated gender-based violence and HIV risk reduction intervention for South African men: Results of a quasi-experimental field trial. Prevention Science. 2009; 10:260-269. doi:10.1007/ s11121-009-0129-x. [PubMed: 19353267]

Kazdin AE, Nock MK. Delineating mechanisms of change in child and adolescent therapy: Methodological issues and research recommendations. Journal of Child Psychology and Psychiatry. 2003; 44:1116-1129. [PubMed: 14626454]

Kelly JA, Murphy DA, Washington CD, Wilson CD, Koob JJ, Davis DR, Davantes B. The effects of HIV/AIDS intervention groups for high-risk women in urban clinics. American Journal of Public Health. 1994; 84:1918-1922. [PubMed: 7998630]

Kelly UA. "I'm a mother first": The influence of mothering in the decision-making processes of battered immigrant Latino women. Research in Nursing \& Health. 2009; 32:286-297. doi: 10.1002/nur.20327. [PubMed: 19350663]

Klosterman KC. Substance abuse and intimate partner violence: Treatment considerations. Substance Abuse Treatment, Prevention, and Policy. 2006; 1:24. doi:10.1186/1747-597X-1-24.

La Greca AM, Silverman WK, Lochman JE. Moving beyond efficacy and effectiveness in child and adolescent research. Journal of Consulting and Clinical Psychology. 2009; 77:373-382. doi: 10.1037/a0015954. [PubMed: 19485580] 
MacKinnon DP, Lockwood CM, Hoffman JM, West SG, Sheets V. A comparison of methods to test the significance of the mediated effect. Psychological Methods. 2002; 7:83-104. doi: 10.1037/1082-989X.7.1.83. [PubMed: 11928892]

Mitrani VB, McCabe BE, Florom-Smith A, Peragallo NP. Predictors of participation in SEPA, a sexual and relational health intervention for Hispanic women. Western Journal of Nursing Research. 2013; 35:849-866. doi:10.1177/0193945913480276. [PubMed: 23493674]

Muthén, LK.; Muthén, BO. Mplus user's guide. Sixth edition.. Author; Los Angeles, CA: 2010.

Peragallo N, DeForge B, O'Campo P, Lee SM, Kim YJ, Cianelli R, Ferrer L. A randomized clinical trial of an HIV-risk reduction intervention among low-income Latina women. Nursing Research. 2005; 54:108-118. [PubMed: 15778652]

Peragallo N, Gonzalez-Guarda RM, McCabe B, Cianelli R. The efficacy of an HIV risk reduction intervention for Hispanic women. Aids and Behavior. 2012; 16:1316-1326. doi:10.1007/ s10461-011-0052-6. [PubMed: 21969175]

Raj A, Amaro H, Cranston K, Martin B, Cabral H, Navarro A, Conron K. Is a general women's health promotion program as effective as an HIV-intensive prevention program in reducing HIV risk among Hispanic women? Public Health Reports. 2001; 116:599-607. [PubMed: 12196620]

Schafer J, Caetano R, Cunradi CB. A path model of risk factors for intimate partner violence among couples in the United States. Journal of Interpersonal Violence. 2004; 19:127-142. doi: 10.1177/0886260503260244. [PubMed: 15005998]

Schwarz G. Estimating the dimension of a model. Annals of Statistics. 1978; 6:461-464.

Straus MA, Douglas EM. A short form of the Revised Conflict Tactics Scales, and typologies for severity and mutuality. Violence and Victims. 2004; 19:507-520. [PubMed: 15844722]

Stuart GL. Improving violence intervention outcomes by integrating alcohol treatment. Journal of Interpersonal Violence. 2005; 20:388-393. doi:10.1177/0886260504267881. [PubMed: 15722492]

Stuart GL, Ramsey SE, Moore TM, Kahler C, Farrell LE, Recupero PR, Brown RA. Reductions in marital violence following treatment for alcohol dependence. Journal of Interpersonal Violence. 2003; 18:1113-1131. doi:10.1177/0886260503255550. [PubMed: 19771712] 


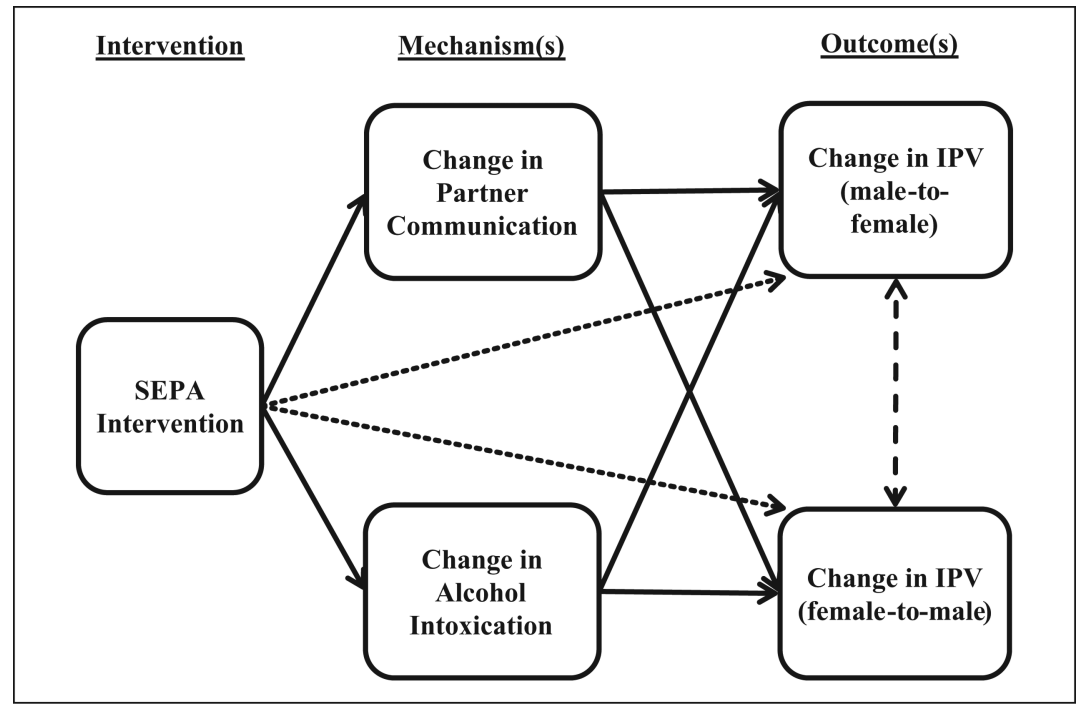

Figure 1.

Model of mechanisms of IPV reduction in SEPA.

Note. Solid lines indicate theorized influences. Dotted lines indicate intervention effects that are theorized to be explained by mechanisms. Dashed line with double arrow indicates theoretical reciprocal effects. IPV = intimate partner violence; SEPA = Salud, Educación, Promoción, yAutocuidado [Health, Education, Promotion, and Self-Care]. 


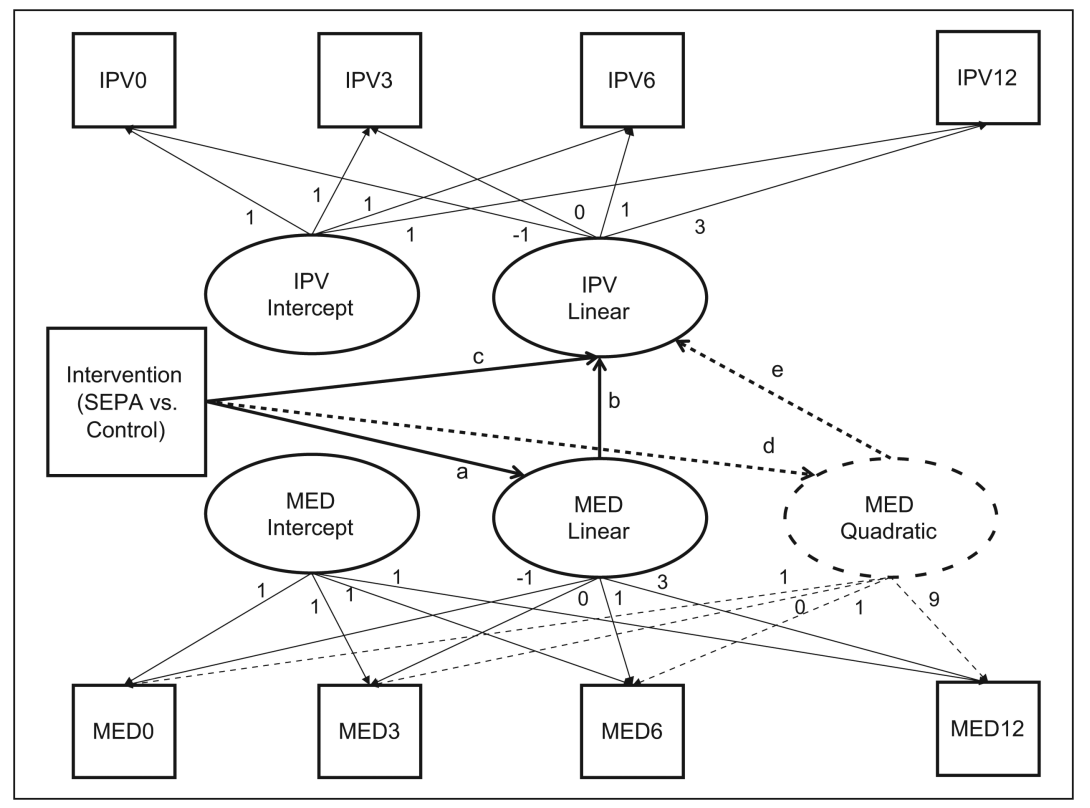

Figure 2.

Generic mediation model for analyses.

Note. Correlations between latent variables omitted for clarity. Quadratic is shown in dashed lines because not all mediators had a quadratic slope. Intercepts are set at 3 months. Path $\mathrm{a}=$ intervention effect on linear change in mediator. Path $b=$ relationship between linear change in mediator and linear change in IPV outcome. Path $\mathrm{c}=$ intervention effect on IPV outcome. Path $\mathrm{d}=$ intervention effect on quadratic change in mediator. Path e = relationship between quadratic change in mediator and linear change in IPV outcome. Timepoint is shown with 0 $=$ baseline and $3=3$-month, $6=6$-month, and $12=12$-month follow-ups. IPV = intimate partner violence outcome (male-to-female or female-to-male); SEPA = Salud, Educación, Promoción, yAutocuidado [Health, Education, Promotion, and Self-care]; MED = Proposed mediator (partner communication about HIV or alcohol intoxication). 


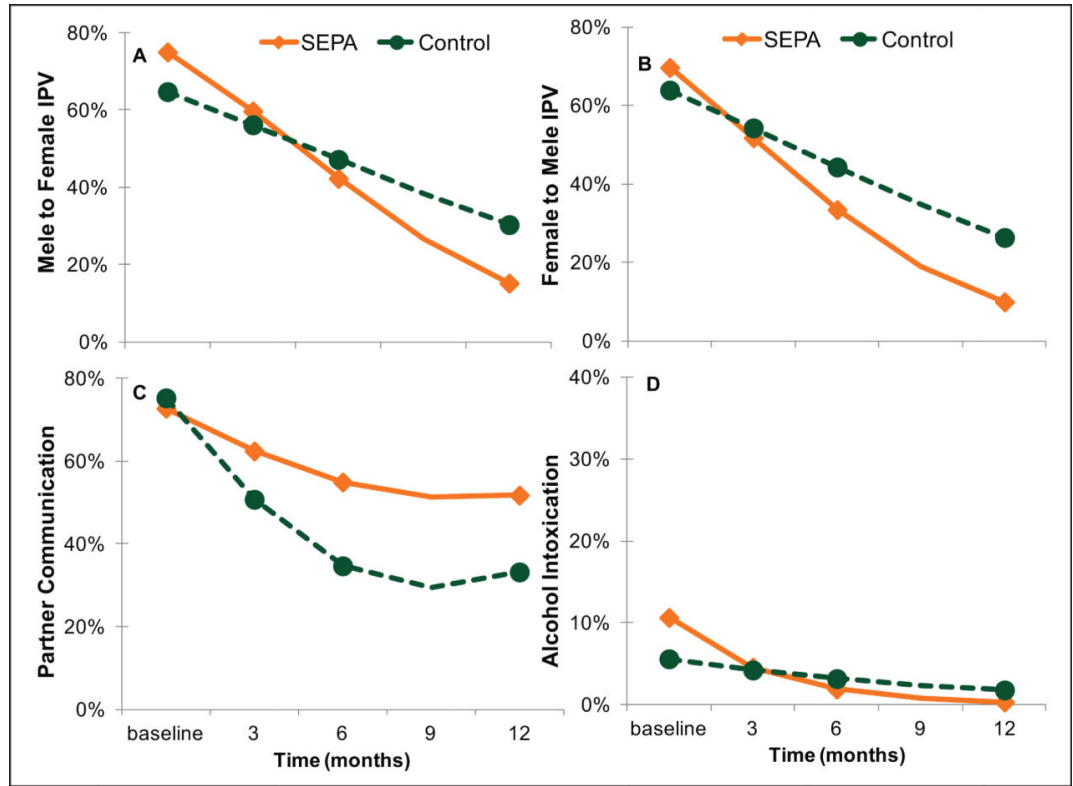

Figure 3.

Estimated trajectories over 1 year of (A) male-to-female IPV, (B) female-to-male IPV, (C) partner communication about HIV, and (D) alcohol intoxication for women in the control condition (dashed lines with circles) and the SEPA condition (solid line with squares). Note. Alcohol intoxication is on a different scale than the other variables due to the low number of women reporting alcohol intoxication in this sample. IPV = intimate partner violence; SEPA = Salud, Educación, Promoción, yAutocuidado [Health, Education, Promotion, and Self-care]. 
Table 1

Baseline Characteristics of Women in the Control and SEPA Conditions.

\begin{tabular}{lcr}
\hline Characteristic & Control $(\boldsymbol{n}=\mathbf{2 7 4})$ \\
\hline Age in years & 38. \\
Education in years & 13. \\
Years residing in United States & 10. \\
Number of sexual partners (past 3 months) & \\
\hline & & \\
\hline & $\boldsymbol{n}(\boldsymbol{\%})$ & $\boldsymbol{n}(\boldsymbol{\%})$ \\
\hline Employed & $88(32)$ & $92(34)$ \\
Monthly income <US\$2,000/month & $185(68)$ & $196(72)$ \\
Born outside of United States & $251(92)$ & $256(93)$ \\
Living withPartner & $199(73)$ & $181(66)$ \\
Has health insurance & $114(42)$ & $92(34)$ \\
IPV (male-to-female) & $166(61)$ & $184(67)$ \\
IPV (female-to-male) & $160(58)$ & $170(62)$ \\
Partner communication about HIV & $185(68)$ & $175(65)$ \\
Alcohol intoxication & $25(9)$ & $37(14)$ \\
\hline Note No signicant & & \\
\hline
\end{tabular}

Note. No significant differences at $p<.05$. Control was a delayed-treatment condition. Partner communication about HIV and IPV were coded as 1 with a positive response to any of these behaviors on this scale. Alcohol intoxication refers to the number reporting intoxication in the past 3 months. SEPA = Salud, Educación, Promoción, yAutocuidado [Health, Education, Promotion, and Self-care]; IPV = intimate partner violence. 

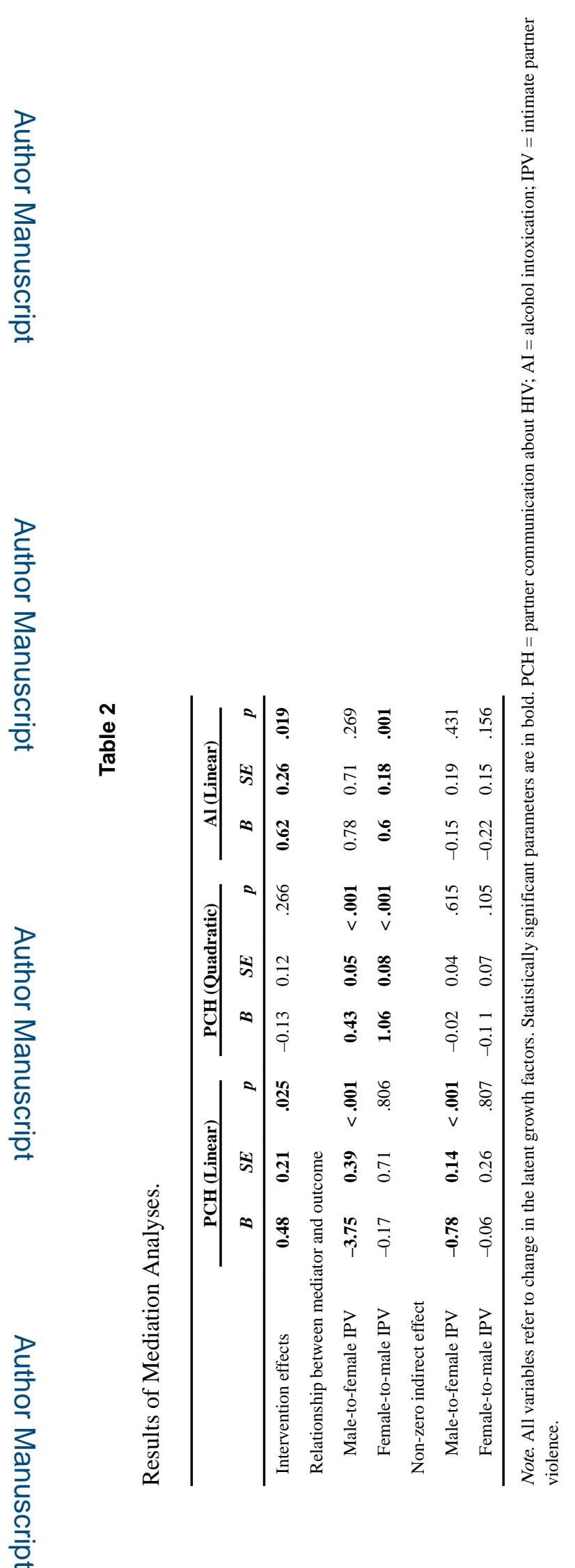